\title{
Epithelial-mesenchymal transitions: the importance of changing cell state in development and disease
}

\author{
Hervé Acloque, ${ }^{1}$ Meghan S. Adams, ${ }^{2}$ Katherine Fishwick, ${ }^{2}$ \\ Marianne Bronner-Fraser, ${ }^{2}$ and M. Angela Nieto'
}

${ }^{1}$ Instituto de Neurociencias (CSIC-UMH), San Juan de Alicante, Spain. ${ }^{2}$ Division of Biology, California Institute of Technology, Pasadena, California, USA.

\begin{abstract}
The events that convert adherent epithelial cells into individual migratory cells that can invade the extracellular matrix are known collectively as epithelial-mesenchymal transition (EMT). Throughout evolution, the capacity of cells to switch between these two cellular states has been fundamental in the generation of complex body patterns. Here, we review the EMT events that build the embryo and further discuss two prototypical processes governed by EMT in amniotes: gastrulation and neural crest formation. Cells undergo EMT to migrate and colonize distant territories. Not surprisingly, this is also the mechanism used by cancer cells to disperse throughout the body.
\end{abstract}

\section{The concept of EMT}

Metazoans consist mainly of two cell types, epithelial and mesenchymal, which differ both morphologically and functionally. Epithelial cells are adherent cells that form coherent layers because they are closely attached by intercellular adhesion complexes (tight junctions, adherens junctions, desmosomes, and gap junctions) in their lateral membranes. They also display apicobasal polarity, with a characteristic basally localized basement membrane that separates the epithelium from other tissues. By contrast, mesenchymal cells are nonpolarized and lack intercellular junctions, such that they can move as individual cells throughout the extracellular matrix (1).

The epithelial and mesenchymal cell phenotypes are not irreversible, and during embryonic development, cells can convert between the epithelial and mesenchymal states. Epithelial-mesenchymal transition (EMT) and its converse, mesenchymal-epithelial transition (MET), are concepts first defined by Elizabeth Hay some 40 years ago (2). Using the chick primitive streak (a structure that forms early in avian, reptile, and mammalian development and that is one of the first signs of gastrulation) as a model, Hay proposed that epithelial cells can undergo dramatic phenotypic changes that reflect their "transformation" to mesenchymal cells (2). However, since this "transformation" is reversible and mesenchymal cells can revert to epithelial cells via MET, the term transition is now preferred. This process of EMT is essential for germ layer formation and cell migration in the early vertebrate embryo (2).

The process of EMT can be delineated into several steps, some of which can occur simultaneously (see Figure 1). Once epithelial cells become competent to respond to EMT-inducing signals, these signals can promote disruption of the intercellular adhesion complexes and loss of the characteristic apico-basal polarity of the epithelial cells (3-5). Cytoskeletal changes are crucial for cells

Authorship note: Meghan S. Adams and Katherine Fishwick contributed equally to this work.

Conflict of interest: The authors have declared that no conflict of interest exists. Nonstandard abbreviations used: BMP, bone morphogenetic protein; Cad7, cadherin 7; EMT, epithelial-mesenchymal transition; FoxD3, forkhead box D3; HNK-1, human natural killer antigen-1; Mesp, mesoderm posterior; MET, mesenchymal-epithelial transition; Sox9, SRY-box-containing gene 9.

Citation for this article: J. Clin. Invest. 119:1438-1449 (2009). doi:10.1172/JCI38019. to leave the epithelium and begin migrating individually. These modifications initially occur by formation of apical constrictions and disorganization of the basal cytoskeleton $(6,7)$. Simultaneously, protease activity leads to breakdown of the basement membrane and cell ingression (8). Thus, upon undergoing EMT, the cells acquire migratory and invasive properties that allow them to migrate through the extracellular matrix.

In this Review, we focus on gastrulation and neural crest formation - two key developmental events that perhaps are the beststudied EMT processes and that illustrate its versatility. Gastrulation is an ancient process fundamental for the formation of the different embryonic layers. By contrast, the neural crest is an evolutionary novelty that is crucial for the formation of a complex peripheral nervous system and for the generation of the vertebrate head (9). We also discuss how defects in gastrulation usually lead to a failure in embryonic development and that while various defects in neural crest development may not be lethal to embryos, they can produce severe congenital malformations. Finally, we discuss how reactivation of some developmental programs leads to malignant EMT in the adult as well as the generation of pathologies such as organ fibrosis and tumor progression.

\section{Overview of EMT during embryonic development}

Primary EMT events (i.e., those that occur in tissues that have never undergone a previous EMT process) take place during implantation of the embryo into the uterus, during gastrulation, and during neural crest formation in amniotes. During embryonic implantation, select cells of the extraembryonic area undergo EMT. One example of this is when extravillous trophectodermal cells do so to infiltrate the endometrium and anchor in the placenta (10).

In the embryo itself, the first EMT event occurs at gastrulation. A subset of cells from the epiblast, the single epithelial cell layer of the embryo, move to the midline to form the primitive streak, a linear structure that bisects the embryo along the antero-posterior axis (see Figure 2A). These cells undergo EMT and internalize to generate mesoderm and endoderm, while those remaining in the epiblast become ectoderm. Thus, the embryo is transformed from a single layer to three germ layers. Mesoderm and endoderm contribute to many tissues of the adult organism that themselves undergo several rounds of EMT and MET (Figure 3A). The terms 
i

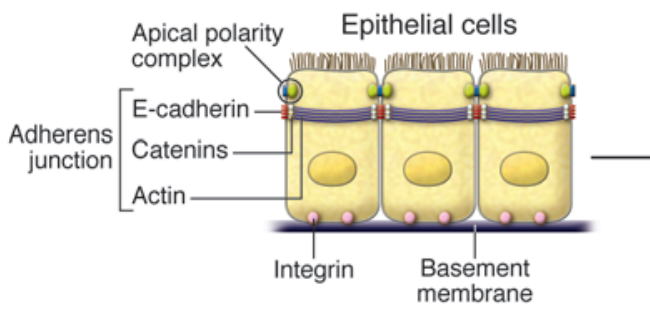

ii

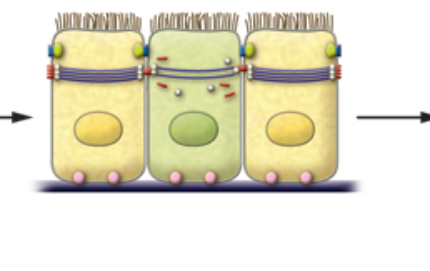

iii

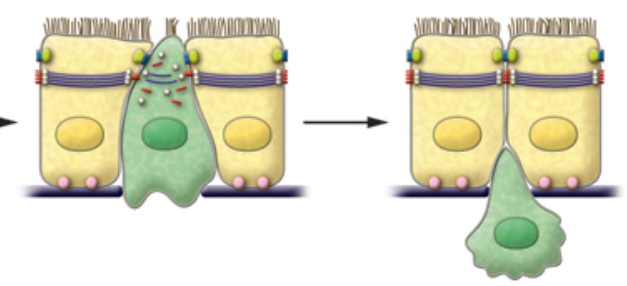

Figure 1

Cellular aspects of EMT. (i) Normal epithelial cells contain adherens junctions composed of E-cadherin together with catenins and actin rings. Tight junctions are associated with apical polarity complexes, while integrins interact with components of the basal membrane. (ii) Loss of cell-cell adhesion. EMT inducers repress the transcription of the genes encoding the components of both adherens and tight junctions, inducing the loss of cell polarity. E-cadherin is internalized and targeted for degradation. (iii) Breakdown of the basal membrane and apical constriction. Profound cytoskeletal remodeling will favor cell delamination by inducing apical constriction and disorganization of the basal membrane. (iv) Cell delamination and invasion. Expression of integrin receptors and continued activation of metalloproteases favors migration through the extracellular matrix and invasion of adjacent tissues.

EMT and MET refer to the process by which cells transition from epithelial to mesenchymal and vice versa, but they are not involved in cell specification or acquisition of cell fate. Rather, these terms refer to cell shape and adhesive properties.

Primary EMT also occurs during vertebrate nervous system development to generate neural crest cells. The epithelial neural plate in the midline of the embryo rolls up to form the cylindrical neural tube, precursor to the brain and spinal cord. Those epithelial cells located near the dorsal midline of the neural tube undergo primary EMT to become migratory neural crest cells, which subsequently move away from the neural tube, navigating along stereotypic pathways throughout the embryo. Initiation of neural crest migration generally occurs following closure of the tube but can occur prior to tube closure, as is the case in the cranial regions of mammals (11). Following their migration, neural crest cells differentiate into many diverse derivatives, including ganglia of the peripheral nervous system, bone and cartilage of the jaws, pigment cells, and glial cells. Formation of these derivatives often requires a MET step, such as during aggregation of postmigratory neural crest cells into sensory ganglia (Figure 3B). Appearance of the neural crest is thought to have facilitated formation of the "new vertebrate head." The main characteristic of this novel evolutionary structure is the acquisition of new sensory functions and the ability to adopt predatory behaviors $(9,12)$.

Primary EMT events such as gastrulation and formation of migratory neural crest cells are followed by the generation of distinct cell types. The mesoderm initially comprises mesenchymal cells and rapidly becomes subdivided into axial, paraxial, intermediate, and lateral plate mesoderm (in turn formed by somatopleure and splanchnopleure), each of which gives rise to multiple derivatives (see Figures 2 and 3). Mesodermal cells distributed along the entire mediolateral axis of the embryo subsequently undergo MET, mostly giving rise to transient epithelia that form the notochord, somites, nephritic ducts, splanchnopleure, and somatopleure. The notochord is derived from the axial mesoderm and is a transient vertebrate structure that confers support to the embryo before the vertebral column develops. Furthermore, it represents an important signaling center for the developing neural tube and somites. Except for the notochord, all the other embryonic structures derived from the early mesoderm are later remodeled by successive EMT and MET events to define the final architecture of different organs and tissues (13). For example, paraxial mesoderm undergoes MET to form somites, which are balls of epithelial cells. The somites subsequently go through another transition, with a portion of the somites undergoing EMT to form the sclerotome, precursor to the vertebrae.

Endodermal derivatives can also use EMT to generate internal organs, such as the pancreas and liver $(14,15)$, although these processes are not as well documented at the molecular level (Table 1). Some cell lineages undergo several cycles of EMT/MET, as occurs during the formation of the cardiac valves, which undergo three cycles of EMT (Table 1; ref. 13).

\section{EMT at gastrulation}

The signaling pathways leading to the formation of the primitive streak. The term gastrulation comes from "gastrae," as first used to describe gut formation in sponges ("gaster" means gut in Greek). Nowadays, "gastrulation" is conventionally used to describe the formation of the three embryonic germ layers, the ectoderm, mesoderm, and endoderm, from the epiblast, the initial epithelial embryonic layer. Ectoderm forms the skin and nervous system; mesoderm forms the skeletal and cardiac muscle, among other derivatives; and endoderm forms the gut. Gastrulation is observed in all metazoans (both diploblasts and triploblasts) and is accompanied by drastic changes that are necessary for remodeling a single epithelial layer such as the epiblast into a complex three-dimensional multilayered embryo. Essentially, this process serves to situate the mesoderm and endoderm inside the embryo. The internalization process can occur through two distinct mechanisms: invagination/involution or ingression. Invagination involves the infolding of an external layer into the interior of the embryo, whereas cell ingression refers to an EMT process whereby individual superficial cells detach from the external epithelial layer and are internalized. Here, we will only refer to ingression, as it is an EMT process and the mechanism used by avian and mammalian embryos.

In chick and mouse embryos, the cells that ingress at the primitive streak receive canonical Wnt signaling activated in the posterior region of the embryo (16). Wnt signaling seems to render these cells competent to respond to other extracellular signals that initiate EMT. Indeed, the primitive streak does not form in 
A

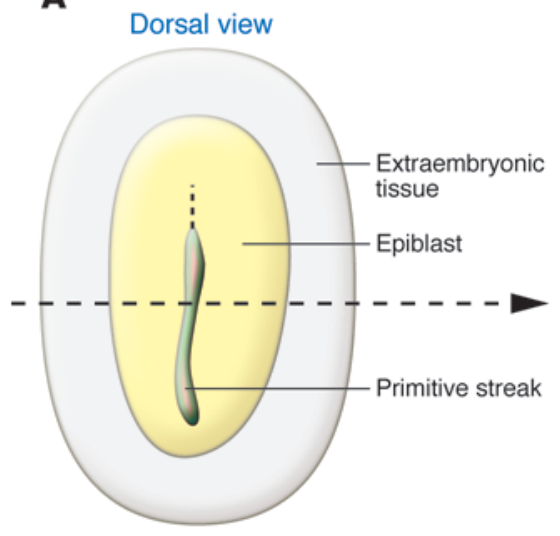

Transverse section

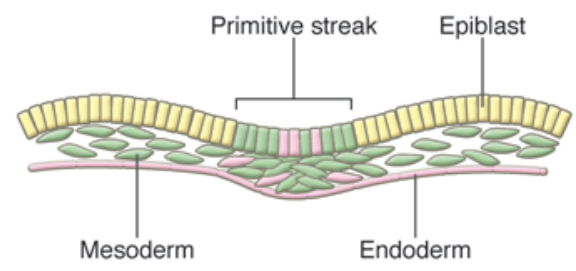

B

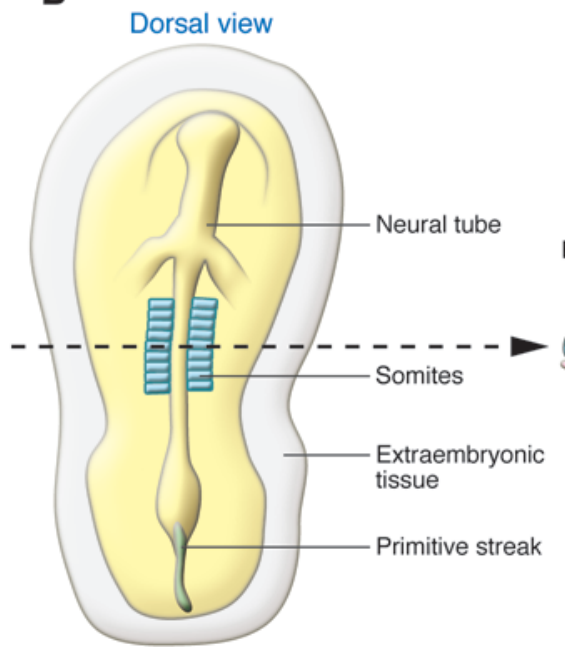

\section{Figure 2}

The formation of embryonic layers at gastrulation in amniotes. Schematic representation of chick embryos as representative of amniotes (birds, reptiles, and mammals). Dorsal views and transverse sections taken at the level of the dotted lines. (A) The embryonic layers are defined during gastrulation. Mesodermal (green) and endodermal cells (pink) are internalized at the primitive streak through a process of EMT, while ectodermal cells remain epithelial (yellow). (B) The mesodermal cells condense to form various derivatives (blue) along the medio-lateral axis of the embryo. The axial mesoderm gives rise to the notochord; paraxial mesoderm epithelializes through a process of MET to form the somites; the intermediate mesoderm will later form the urogenital system; and the lateral mesoderm condenses to form somatopleure and splanchnopleure. The ectodermal cells contribute to the neural tube or the epidermis. The endoderm is shown in pink.
Wnt3-deficient mice, in which EMT does not occur (17). Conversely, mouse embryos overexpressing Wnt8c develop multiple primitive streaks (18). Downstream of Wht signaling, proteins of the TGF- $\beta$ superfamily, such as Nodal and Vg1, are key inducers of gastrulation in different species (19). Ectopic Vg1 expression alone is sufficient to induce the formation of an additional primitive streak in the chick blastula (20), and more than $50 \%$ of embryos mutant for the two Vg1 mouse homologs (GDF1 and GDF3) develop mesodermal defects (21).

Nodal signaling appears to induce EMT as cells ingress during mouse gastrulation, as highlighted by the failure of Nodal mutants to complete gastrulation. This phenotype can be rescued by transplantation of a few Nodal-expressing cells from wild-type embryos, suggesting that low levels of secreted Nodal are sufficient to drive ingression (22). The lower layer of the embryo (the hypoblast in the chick and the visceral endoderm in the mouse) secretes inhibitors of Nodal, which define the correct positioning of the streak and inhibit the formation of ectopic primitive streaks $(23,24)$. Thus, once Wnt signaling makes the epiblast competent to gastrulate, the cooperative activity of $\mathrm{Vg} 1$ and Nodal induces the formation of the primitive streak and mesoderm ingression (Figure 4). Signaling through FGF receptors (FGFRs) seems to be necessary to maintain the EMT regulatory network $(25,26)$. Indeed, in FGFR1deficient mice, the primitive streak and mesodermal cells initially form, but their production is arrested (25).
Transcription factors downstream of signaling events in the primitive streak. Signaling events activate transcription factors that mediate EMT. In response to signals from Wnt, TGF- $\beta$, and FGF family members, cells activate transcription factors that in turn induce EMT (Figure 4). Members of the Snail family of zinc finger transcription factors are key molecules and are expressed in the primitive streak (27). Embryos lacking Snail activity fail to gastrulate, leading to an accumulation of epithelial cells still expressing E-cadherin that are unable to migrate $(28,29)$. Snail genes are induced in vitro and in vivo by cytokines of the TGF- $\beta$ superfamily, and FGF-initiated signaling seems necessary to maintain Snail 1 expression in the mouse primitive streak (25). Despite early studies in Drosophila leading to the proposal that snail is a mesodermal determinant $(30,31)$, there is no evidence that this gene family is involved in mesoderm specification. For example, mesoderm specification is not altered in Snail1-deficient mice; however, those mesodermal cells that form are unable to migrate as they fail to downregulate E-cadherin expression and thus retain cell-cell contacts. This is consistent with the existence of independent pathways governing cell fate specification and EMT during gastrulation (32). It is interesting to note that depending on the cellular context, the control of cell adhesion and migration by Snail may be expressed as full EMT, such as at the primitive streak in amniotes, or as collective cell migration, as occurs during axial mesendoderm migration in zebrafish (33) and during re-epithelialization of skin wounds in mice (34). 


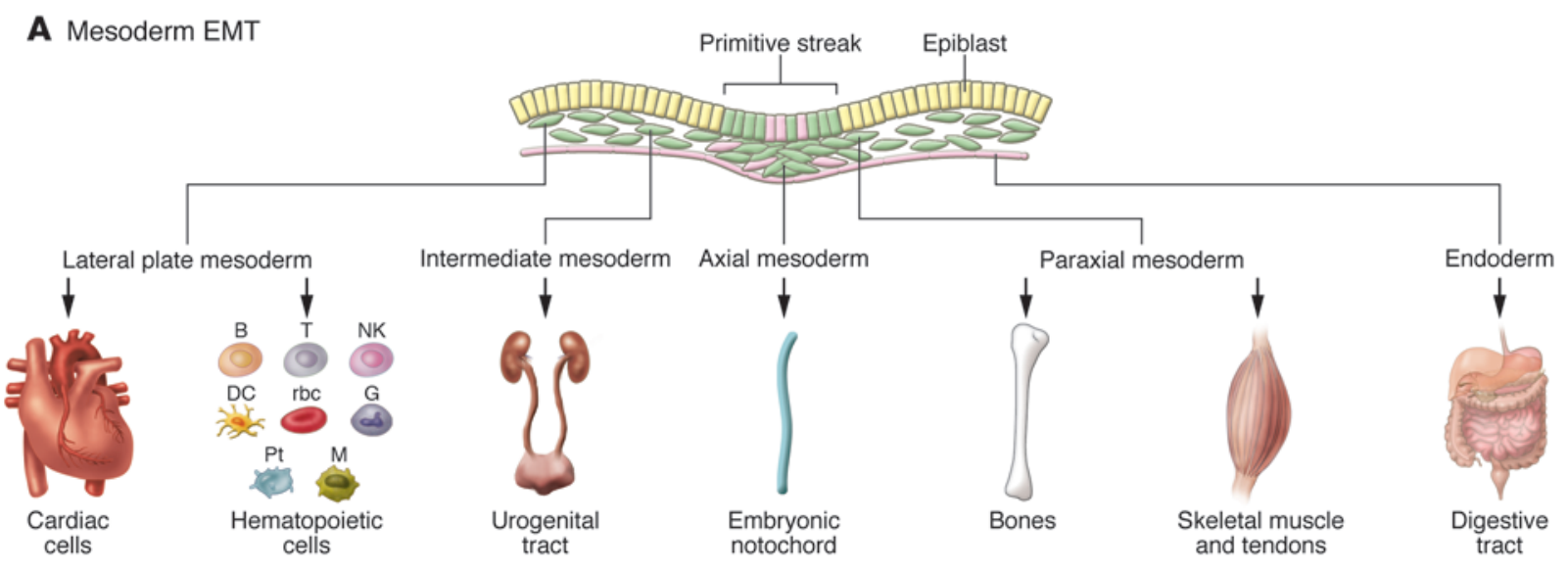

\section{B Neural crest EMT}
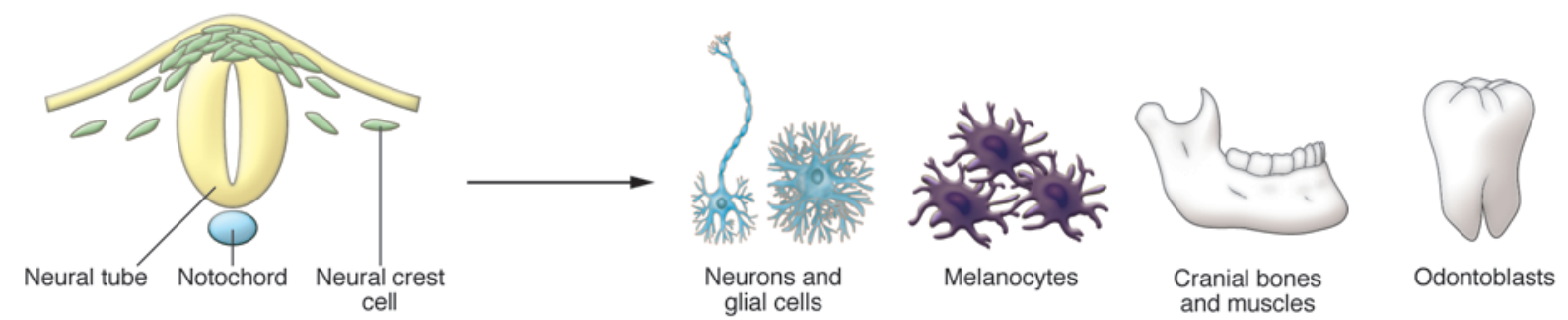

Figure 3

Primary EMTs give rise to progenitors of many organs and tissues. (A) Epiblast cells that internalize at gastrulation give rise to different mesodermal and endodermal populations from which a variety of cell types form. Embryonic cells undergoing EMT are shown in green. Pt, platelets; B, T, and NK, lymphocytes; G, granulocytes; M, macrophages. (B) In turn, the neural crest delaminates from the dorsal neural tube and will generate neurons of the peripheral nervous system, glial and satellite cells, pigment cells, odontoblasts, and the craniofacial cartilage, as well as other cell types.

In the mouse, other transcription factors have recently been described as important elements in the control of EMT at gastrulation (Figure 4). Conditional inactivation of eomesodermin (Eomes) in the epiblast blocks EMT and mesoderm delamination, and although these mutant mice express Snail in the primitive streak, E-cadherin mRNA is only partially downregulated. It seems that eomesodermin increases the ability of Snail to repress E-cadherin through an unknown mechanism, perhaps involving induction of transcriptional partners of Snail or the epigenetic control of the availability of Snail-binding sites (35). Other recent studies have highlighted the role of mesoderm posterior (Mesp) transcription factors in inducing EMT in a Wnt-independent manner. Differentiated ES cells overexpressing either Mesp1 or Mesp2 undergo EMT through activation of the EMT inducers Snail and Twist (36), accounting for the block of mesodermal delamination from the primitive streak previously observed in mice lacking both Mesp1 and Mesp2 (37). Interestingly, as in Snail-deficient mice, mesoderm specification is not affected in the Mesp $1^{-/-}$Mesp2 $2^{-/-}$mice.

One consequence of the induction of EMT by Snail is the direct repression of E-cadherin expression (38-40), which, in turn, leads to the disruption of adherens junctions. However, it is worth noting that the Snail proteins are not only E-cadherin repressors but also regulators of the epithelial phenotype (4). Snail also represses expression of genes encoding tight junction components, such as claudins and occludins (41), as well as genes important for apicobasal polarity such as Crumbs 3 and Discs large (5).
Nontranscriptional regulation of E-cadherin expression. Posttranscriptional events are also important for EMT. Gastrulation is a rapid process, and some of the proteins that must be downregulated for EMT to proceed (e.g., E-cadherin) have a long half-life. Thus, the regulation of gene transcription is not sufficient for gastrulation to proceed. Recent studies have revealed that posttranscriptional regulatory mechanisms are in play (Figure 4). An $N$-ethyl $N$-nitrosourea-induced (ENU-induced) mutagenesis screen identified two mouse mutants with impaired expression of an activator of p38 MAPK, p38-interacting protein (p38IP) (42). Although these mutant embryos can specify mesoderm, the cells do not undergo EMT and do not migrate normally due to impaired downregulation of E-cadherin protein. This phenotype is very similar to those observed in FGFR1-, FGF8-, and Snail1-deficient mice (29, $43,44)$, although it is independent of the FGF pathway and Snail activation. Thus, it seems that p38 MAPK and p38IP may promote the active and rapid degradation of E-cadherin protein in cells undergoing EMT (42).

The mechanism by which $\mathrm{p} 38$ regulates E-cadherin protein turnover is still unknown, but it may be related to the control of E-cadherin trafficking, as occurs in mice lacking ADP-ribosylation factor-related protein 1 (ARFRP1) activity. These embryos fail to gastrulate after detachment of the epiblast and subsequently undergo apoptosis (45) due to the disruption of E-cadherin trafficking through the Golgi apparatus (46).

Another mutant mouse strain also obtained from an ENUinduced mutagenesis screen (lulu mutant mice) corresponds to a 
Table 1

EMT processes during vertebrate embryonic development

\begin{tabular}{|c|c|c|}
\hline Process & $\begin{array}{l}\text { Epithelium } \\
\text { of origin }\end{array}$ & $\begin{array}{c}\text { Newly formed } \\
\text { mesenchymal tissue }\end{array}$ \\
\hline \multicolumn{3}{|l|}{ Primary EMT } \\
\hline \multirow{5}{*}{$\begin{array}{l}\text { Gastrulation } \\
\text { (EMT at the } \\
\text { primitive streak) }\end{array}$} & Epiblast & Axial mesoderm \\
\hline & & Paraxial mesoderm (somites) \\
\hline & & Intermediate mesoderm \\
\hline & & Lateral plate mesoderm \\
\hline & & Endoderm \\
\hline $\begin{array}{l}\text { Neural crest } \\
\text { formation }\end{array}$ & $\begin{array}{c}\text { Dorsal } \\
\text { neural tube }\end{array}$ & Neural crest mesenchyme \\
\hline
\end{tabular}

Derivatives

Refs.

Embryonic notochord

105

Skeletal muscles, bones, tendons, satellite cells, components of vertebrae and ribs, vertebral arteries

Urogenital system

Cardiac cells, mesenteries, and peritoneal cells, conjunctive tissue of the body wall, blood vessels, HSCs

Digestive and respiratory tract

Neurons of peripheral nervous system; glial cells; 106 pigment cells; endocrine cells of the adrenal medulla and $C$ cells of the thyroid; facial cartilage and bone; odontoblasts; dermis; connective tissue of cranial muscles and salivary, lachrymal, thymus, thyroid, and pituitary glands; meninges of the forebrain; smooth muscle and adipose tissue of skin, head, and neck; VSMCs

\section{Secondary EMT}

Somite decondensation

Ventral half

of the somite

Sclerotome

\begin{tabular}{lll}
$\begin{array}{l}\text { Lateral plate } \\
\text { mesoderm }\end{array}$ & $\begin{array}{c}\text { Dorsal part } \\
\text { of the somite } \\
\text { Somatopleure }\end{array}$ & Myotome \\
& Splanchnopleure & $\begin{array}{l}\text { Mngioblasts } \\
\text { HSCs } \\
\text { Endocardial progenitors }\end{array}$ \\
& Palatal shelf & $\begin{array}{l}\text { Palatal mesenchymal cells } \\
\text { Secondary palate }\end{array}$ \\
$\begin{array}{l}\text { Pancreas } \\
\text { Liver }\end{array}$ & Pancreatic bud \\
$\begin{array}{l}\text { Tertiary EMT } \\
\text { Cardiac valve } \\
\text { formation }\end{array}$ & Liver diverticulum & $\begin{array}{l}\text { Endocrine cells } \\
\text { Hepatoblast }\end{array}$ \\
\hline
\end{tabular}

Neural arches, ribs, syndetome, vertebral body, intervertebral discs, endothelial cells, tendons, meninges of the spinal cord, blood vessels, vertebral joints, perineurium, endoneurium

Satellite cells, smooth muscle

Connective tissues of limbs, body wall muscles

Blood vessels

Blood cells

Heart cells

Sertoli cells

Palatal closure

Hepatocytes

Cardiac valves
Endocrine cells of Langerhans islets null allele of the FERM domain gene erythrocyte protein band 4.1like 5 (Epb4.1l5). lulu mutants die early during embryonic development due to gross morphological defects resulting from a failure of EMT at gastrulation (47). E-cadherin transcription is inhibited in Epb4.115-/- mice, but the protein is not downregulated, further supporting the existence of posttranslational regulation of E-cadherin expression at gastrulation. Epb4.115 can bind to p120 and inhibit its association with E-cadherin at adherens junctions, contributing to the gastrulation phenotype in lulu mutants (48).

A key component of epithelial junctions is $\beta$-catenin, which is part of the protein complex that connects cadherins to the actin cytoskeleton at adherens junctions. In response to exogenous signals such as those provided by Wnts, $\beta$-catenin is translocated from the cell membrane to the cytoplasm, where it is either ubiquitinated and degraded or directed to the nucleus, where it can regulate gene expression and induce EMT. Thus, the relationship between the E-cadherin and $\beta$-catenin pools is crucial for the regulation of the epithelial phenotype. Interestingly, Snail interacts with $\beta$-catenin and stimulates its transcriptional activity (49), suggesting a new level of regulation of EMT.

Changes in cell shape and basal membrane disruption. A fundamental event during EMT is the loss of cell polarity. As mentioned above, Snail1 directly represses Crumbs 3 transcription, abolishing the localization of the Par complexes and the cell polarity proteins Crumbs to the tight junctions (50). Another link between proteins with polarized membrane distribution and the regulation of tight junctions was also recently revealed after it was discovered that the bidirectional signaling molecule EphrinB1, previously shown to regulate cell adhesion at morphological boundaries, associates with the Par protein Par6. This 

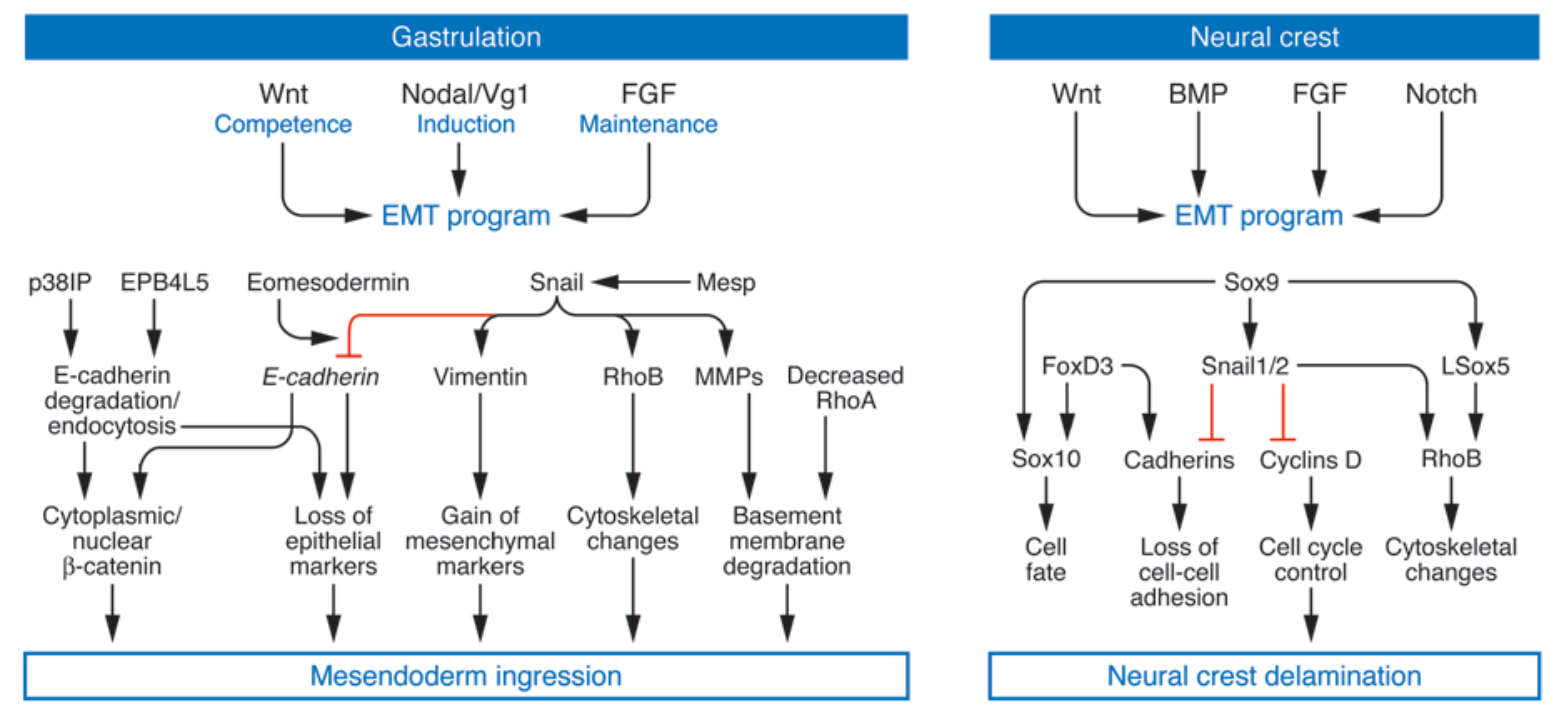

\section{Figure 4}

Similar signaling pathways control the EMTs at gastrulation and neural crest delamination in the amniote embryo. Signaling molecules of the TFG- $\beta$ superfamily (Nodal, Vg1, and BMPs), together with Wnt and FGF, initiate the formation of the primitive streak and operate at the neural folds to drive the ingression of the mesendoderm and the delamination of the neural crest, respectively. Some downstream targets are also conserved, such as the Snail genes. While Snail factors are key regulators of the EMT program during gastrulation, the coordinated induction of several transcription factors is required to control the robust program of neural crest delamination. EPB4L5, FERM and actin-binding domaincontaining band 4.1 superfamily member; p38IP, p38-interacting protein; Rho, members of the Rho family of small GTPases.

binding inactivates the polarity complex by preventing Par6 from binding to Cdc42, thereby disrupting tight junctions (51).

To complete EMT, cells must pass through the basal membrane and delaminate from the epithelial cell layer. The activation of metalloproteases helps to degrade the basal membrane, and in vitro studies have documented the activation of MMP2, MMP3, and MMP9 by Snail genes $(52,53)$, suggesting they may fulfill a similar function in vivo during gastrulation. In addition to metalloproteases, the small GTPase RhoA was recently implicated in the control of microtubule dynamics and basal membrane integrity in the chick primitive streak (6), representing another mechanism for disrupting the basement membrane.

In summary, cell fate specification and the induction of morphogenetic movements are governed independently during gastrulation. Although we have learned much about the many important factors involved in these processes, we remain far from understanding the gene regulatory networks and the mechanisms employed to regulate protein stability and turnover. Accordingly, efforts to define the transcriptome that is active from gastrulation to organogenesis in the mouse embryo may be extremely helpful in defining the global network of EMT programs (54). Although the data on human gastrulation are very scarce, histological analysis from gastrulating human embryos are highly suggestive of an EMT process occurring at the primitive streak, as expected (55). The isolation of human and simian ES cells has allowed the development of an in vitro model to study primate gastrulation $(56,57)$. EMT also occurs during spontaneous differentiation of human ES cells, and it is associated with the induction of EMT effectors such as Snail, repression of E-cadherin, and an increase in vimentin expression (58).

\section{EMT during neural crest cell emigration}

Neural crest cells emigrate from the neural tube following a classical EMT whereby neuroepithelial cells in the dorsal neural tube are transformed into a migratory mesenchymal phenotype (11). Premigratory neural crest cells form at the border of the neural plate and non-neural ectoderm $(11,59)$ as a result of signals emanating from these two tissues that define the "neural plate border specifier" (60). The dorsal neural folds contain these precursors, and further signaling refines a subpopulation of these cells as premigratory neural crest cells that express "neural crest specifier" genes, such as members of the Sox and Snail families and forkhead box D3 (Foxd3) (60, 61) (Figure 4). These precursor cells then undergo EMT to become migratory neural crest cells, delaminating from the neural folds and migrating to distinct regions of the developing embryo prior to their reaggregation via MET and further differentiation.

Signaling cascades mediating EMT in the neural crest. Studies by many laboratories have provided a general picture of the gene regulatory network that operates during neural crest development (62). Interestingly, the signaling pathways utilized during EMT in the neural crest are similar to those that are active at the primitive streak during gastrulation (Figure 4). Indeed, a combination of Wnt, FGF, and bone morphogenetic protein (BMP) signaling pathways is necessary for neural crest induction (63). Canonical Wnt signaling regulates several important stages of neural crest development, from induction and the proliferation of neural crest precursors to delamination of migratory neural crest cells from the neural tube through the modulation of cell division (64). Noncanonical Wnt signaling is also important for neural crest cell migration (65).

TGF- $\beta$ superfamily signaling in the neural crest mainly involves BMPs. In chick embryos, BMP4 is expressed in the neural folds and converts competent epithelial neural plate cells into migratory neural crest cells through activation of $c-m y b(66)$, which, in turn, activates transcription of msh homeobox 1 (Msx1) and Snail2 (63, $66,67)$. BMPs also seem to regulate the timing of neural crest cell migration, since Noggin, an inhibitor of BMPs, prevents delamination until it is downregulated by signals emanating from the 

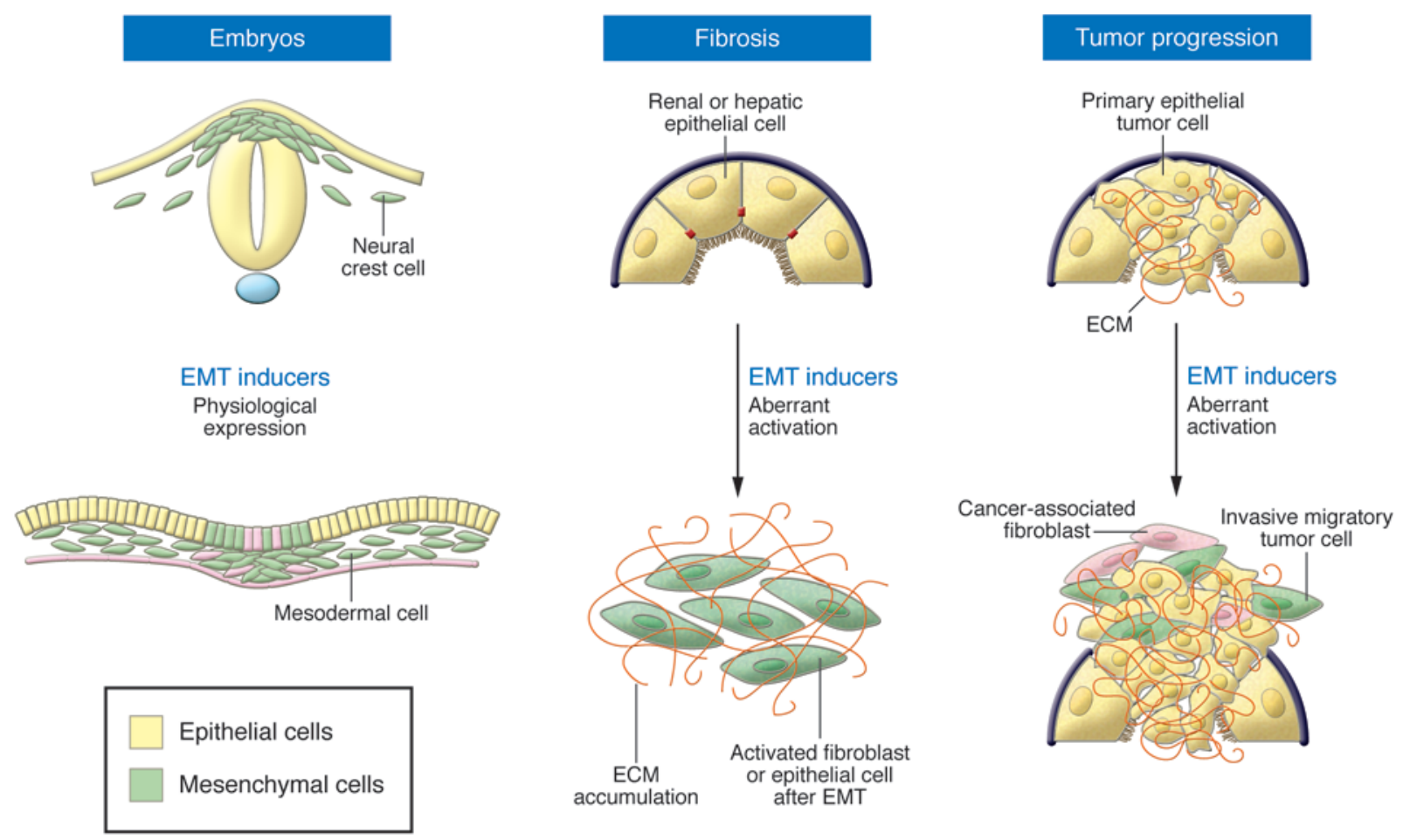

\section{Figure 5}

EMTs in development and disease. EMTs (cells in green) occur during normal embryonic development, such as during neural crest cell delamination from the dorsal neural tube and mesendoderm ingression from the primitive streak. While EMT inducers are usually maintained in a silent state in the adult, they are reactivated during organ fibrosis and at the invasive front of human carcinomas during tumor progression.

somites $(66,68)$. Another regulator of BMP signaling in the neural crest is $\mathrm{Cv}-2$, a vertebrate homolog of Drosophila crossveinless, which controls the onset of migration in the trunk but not in cranial neural crest cells (69). Additionally, BMP signaling increases Wnt1 expression, whereas inhibition of Wnt1 results in lower levels of BMP targets, strongly suggesting that these two signaling pathways are connected during EMT in the neural crest (70).

Experimental evidence has long demonstrated that Notch signaling is also necessary for cranial neural crest development (71). Whether Notch is necessary for the EMT that occurs in these cells is not clear, although the contribution of Notch signaling to the development of these cells in the frog and chick has been tested through the expression of Snail2, which is more closely associated with EMT than with specification of the neural crest cell fate (27).

Associated transcriptional networks. The coordinated action of SRYbox-containing gene 9 (Sox9), Foxd3, and Snail genes (72) is necessary for neural crest EMT (Figure 4). Foxd3 is expressed in premigratory and migratory neural crest cells. Overexpression of Foxd3 promotes the expression of markers of migratory neural crest cells, such as human natural killer antigen-1 (HNK-1) and cadherin 7 (Cad7), which are associated with increased neural crest delamination (73), although the upregulation of HNK-1 only appears 2 days after FoxD3 overexpression. This suggests the need for a permissive step before FoxD3 can promote neural crest cell emigration, consistent with data indicating that Foxd3 overexpression alone is insufficient for neural crest cell EMT (74).

Snail2 is necessary for neural crest EMT, and it is sufficient to induce neural crest cell generation and delamination in cranial regions $(28,75)$ but not in the trunk. Rhob is a target of Snail2 and, as a regulator of the cytoskeleton, is required for delamination, rather than specification, of neural crest cells (76). The Sox E genes (Sox8, Sox9, and Sox10) can all induce ectopic migration of neuroepithelial cells from the neural tube and expression of HNK-1 and may also functionally compensate for one another. An example of this is in the mouse, where Sox 8 function can be substituted by Sox 9 and Sox 10 (77). Sox9 is also thought to be responsible for maintaining cells in an undifferentiated state (78). In contrast to Snail2, Sox9 is required for the development of the trunk neural crest but not the cranial neural crest (72). Overexpression of either Sox 9 or Rhob is not sufficient to induce complete EMT or neural crest cell delamination, but their combined overexpression results in a large number of $\mathrm{HNK}-1^{+}$cells exiting the neural tube $(72,78)$. Chick Sox5, which encodes a member of the group D family of Sox proteins, is part of the hierarchy of genes expressed during neural crest cell emigration from the dorsal neural tube, and it may directly induce Rhob expression (79). Thus, a combination of several transcription factors generates the full spectrum of phenotypic changes associated with EMT and migration from the neural tube. Moreover, the lack of individual genes may be compensated for by the others.

Regulation of the cadherin proteins. A crucial step in neural crest delamination is the transition from a phenotype of tightly coupled and polarized epithelial cells to that of individual mesenchymal cells. Therefore, an important step in the initiation of neural crest cell migration is the decrease in cell-cell adhesion. A critical element in the adhesion of a cell to its neighbors is the expression of cadherins or other components of the cell junction complexes. Loss of E-cadherin can occur through several 
Table 2

The neural crest and human congenital malformations

$\begin{array}{ll}\begin{array}{l}\text { Gene } \\ \text { AP2 (TFAP2A) }\end{array} & \begin{array}{c}\text { Disease } \\ \text { Branchiooculofacial } \\ \text { syndrome (BOFS) }\end{array} \\ & \\ \text { FLI1 } & \begin{array}{l}\text { Paris-Trousseau type } \\ \text { thrombocytopenia } \\ \text { (homozygous deletion of FL/1) }\end{array} \\ \text { FOXD3 } & \text { Vitiligo } \\ \text { PAX3 } & \text { Waardenburg-Shah } \\ & \text { syndrome types 1 and 3 } \\ & \text { Tumors } \\ \text { ZEB2 (SIP1, } & \text { Mowat-Wilson syndrome } \\ \text { ZFHX1B, } & \\ \text { SMADIP1) } & \\ \text { Snail2 } & \text { Waardenburg-Shah syndrome 2 } \\ & \text { Piebaldism (non-Kit-related) }\end{array}$

SOX9 Campomelic dysplasia

$\begin{array}{ll}\begin{array}{l}\text { SOX10 haplo- } \\ \text { insufficiency }\end{array} & \text { HSCR } \\ & \text { Waardenburg-Shah syndrome } 4 \\ \text { TBX1 } & \text { DiGeorge syndrome } \\ \text { TGFBR1 } & \begin{array}{r}\text { LDS1A; LDS2A; non-FBN1-related } \\ \text { Marfan syndrome }\end{array} \\ & \\ \text { TGFBR2 } & \begin{array}{r}\text { LDS type 1B and 2B; non-FBN1- } \\ \text { related Marfan syndrome }\end{array}\end{array}$

Treacle Treacher-Collins syndrome

Twist Saethre-Chotzen syndrome
Disease characteristics

Refs.

Low birth weight, retarded postnatal growth, bilateral branchial cleft sinuses, congenital strabismus, obstructed nasolacrimal ducts, broad nasal bridge, protruding upper lip, carp mouth; occasionally coloboma, microphthalmia, auricular pits, lip pits, highly arched palate, dental anomalies, subcutaneous cysts of the scalp

Mental retardation, facial dysmorphism, clinodactyly, pyloric stenosis, thrombocytopenia

Autosomal dominant vitiligo

Dystopia canthorum, and type 3 also includes contractures or hypoplasia of upper-limb joints and muscles

Rhabdomyosarcoma, tumors of ncc origin including melanoma and neuroblastoma 118

HSCR associated with microcephaly, mental retardation, hypertelorism, submucous cleft palate, short stature

Defects in melanocytes, also seen with Mitf mutation

Congenital white forelock, scattered normal pigmented and hyperpigmented macules, triangular shaped depigmentation patch on forehead; caused by heterozygous deletion of Snail2

Congenital skeletal malformation syndrome, includes cleft palate, low-set ears, loss of the 12th pair of ribs, abnormal pelvic bones, small chest and hip dislocations; may include absence of the olfactory bulbs, renal and/or cardiac defects, and $X Y$ sex reversal with genital malformations; frequently associated with conductive and sensorineural hearing loss

Failure of enteric ganglia to populate the distal colon

Deafness/pigmentation defect in addition to HSCR; also seen in EDN3 and EDNRB mutants

Cardiac outflow tract anomalies, absence or hypoplasia of the thymus and parathyroid glands, nasal voice (often associated with cleft palate or submucosal cleft palate), and facial dysmorphism, known as conotruncal anomaly face

LDS1 and -2 are clinically indistinguishable autosomal dominant aortic aneurysm syndromes characterized by arterial tortuosity and aneurysms, hypertelorism, and bifid uvula or cleft palate; type 1 category has craniofacial involvement consisting of cleft palate, craniosynostosis, or hypertelorism. Type 2 category had no evidence of these traits, but some patients had a bifid uvula. Marfan syndrome shows striking pleiotropism and clinical variability. The cardinal features occur in 3 systems: skeletal, ocular, and cardiovascular; a highly arched palate with crowding of the teeth is a frequent skeletal feature.

Antimongoloid slant of the eyes, coloboma of the lid, micrognathia, microtia and other ear deformities, hypoplastic zygomatic arches and macrostomia; often conductive hearing loss and cleft palate

Craniosyntosis, limb deformities, and dysmorphic facial features including facial asymmetry
115

AP2, transcription factor AP-2a; EDN3, endothelin 3; EDNRB, endothelin receptor type B; FBN1, fibrillin-1; FLI1, Friend leukemia virus integration 1; HSCR, Hirschsprung disease; LDS, Loeys-Dietz syndrome; Mitf, microphthalmia-associated transcription factor; ncc, neural crest cell; PAX3, paired box 3 ; SIP1, Smad interacting protein 1; SMADIP1, Smad interacting protein 1; TBX1, T-box 1; TGFBR, TGF- $\beta$ receptor; ZEB2, zinc finger E-box binding protein 2; ZFHX1B, zinc finger homeobox $1 \mathrm{~b}$.

mechanisms, although, as previously discussed, transcriptional repression seems to be the most common.

Snail transcription factors bind to conserved E-box sequences within the promoters of their target genes, such as E-cadherin (38), as well as the genes encoding claudin-3, claudin-4, claudin-7, and occludin (41). Transcription factors of the Zeb family also bind to these target sites and function as E-cadherin repressors (4). Interestingly, in embryos of zinc finger E-box-binding homeobox 2-null (Zeb2-null) mice, the vagal neural crest is absent (80). Whether E-cadherin levels are regulated by posttranscriptional mechanisms 
during neural crest delamination is not clear, but it would be interesting to investigate whether this tissue is subject to processes similar to those that occur during gastrulation.

E-cadherin is not the only cadherin that must be repressed for EMT to occur in all cell types. In the chick, Cad6B is expressed within the neural folds, and the gene encoding it is known to be a direct target of Snail2, which binds E-box elements within the cadherin- $6 B$ promoter to repress transcription (81). Another type I cadherin, $\mathrm{N}$-cadherin, is also present in the neural plate, where it inhibits neural crest delamination both through a cell adhesiondependent mechanism and by repressing canonical Wnt signaling. Interestingly, $\mathrm{N}$-cadherin protein, but not mRNA, is downregulated at the onset of neural crest cell migration, and a cleaved fragment of $\mathrm{N}$-cadherin can promote neural crest delamination (82). Subsequently, expression of $\mathrm{N}$-cadherin returns in specific lineages such as the dorsal root ganglia as the cells reaggregate (83). As neural crest cells exit the neural tube, they express cadherins such as Cad7 and Cad11, rather than E-cadherin and Cad6B $(84,85)$. This indicates that different cadherins fulfill different functions in the premigratory and the migratory neural crest cell populations. Thus, a cadherin switch occurs during the EMT, so that some cadherins are important for maintaining epithelial cell character (e.g., Cad6B), whereas others are involved in cell migration after the EMT has occurred (e.g., Cad7 and Cad11).

The role of the extracellular matrix. In addition to changes in cellular adhesion, the breakdown of the basement membrane that surrounds the neural tube is a necessary step to complete a full EMT and allow the migration of cranial neural crest cells (86), analogous to the situation during gastrulation. This has been observed in both mice and birds (86).

MMP2 is an important protein in the degradation of various extracellular matrix molecules, including collagen type I, IV, V, VII, X, and XI, as well as elastin, gelatins, laminin, aggrecan, and vitronectin (87). It is expressed during EMT in several cell types, including migrating neural crest cells, and is rapidly downregulated as the neural crest cells migrate away from the site at which they form. MMP inhibitors, including BB-94 and tissue inhibitor of metalloprotease-2 (TIMP-2), prevent EMT in vitro and in vivo during neural crest formation. Additionally, craniofacial mesenchyme does not disperse properly in the Patch mouse mutant, which has lost the $\alpha$ subunit of PDGFR and displays less MMP2 activity (88). Indeed, specific morpholino knockdown of MMP2 expression in the dorsal neural tube perturbs neural crest cell EMT (89).

The extracellular matrix is not a passive structure that allows the movement of neural crest cells. Rather, it provides an active input for cell migration from the neural tube. In this matrix, fibronectin, laminins, and proteoglycans support and allow cell movement (90), and the different integrin molecules expressed by the neural crest cells recognize these extracellular matrix components, favoring the correct regulation of migration.

In epithelial cells that overexpress Snail1, Snail2, or E-47, another EMT inducer, expression of the extracellular matrixmodifying protein TIMP-1 is upregulated, as is transcription of the genes encoding collagen type $1 \alpha 2$ and integrin- $\alpha 5$, whereas transcription of the genes encoding keratin-19 and integrin- $\beta 6$ diminishes (91). Much work has been done to understand the many interactions among the extracellular matrix, E-cadherin, and adherens junctions in cancer cells, which may help in analysis of the role of the extracellular matrix in neural crest cell EMT (for instance, ref. 92).
In summary, although similar signaling pathways operate during the EMT that occurs at the primitive streak and at the neural folds, the signals transduced activate common and distinct targets. One important difference is that while defects in individual genes lead to very strong EMT phenotypes at gastrulation, a high degree of cooperation and plasticity is in play during neural crest development. This imbues the system with further robustness, perhaps because the neural crest is an evolutionary novelty fundamental for the development of the vertebrate head. Accordingly, it is worth noting that although Snail proteins are crucial for gastrulation in all metazoans studied to date $(28,29,93)$, the analysis of the role of Snail genes in neural crest development indicates that mutant mice can still generate neural crest even though they present multiple craniofacial defects (94).

\section{The neural crest and congenital malformations}

Mutations in genes involved in neural crest EMT are often associated with congenital defects. Defects in individual genes usually have mild effects, possibly due to gene redundancy or plasticity. However, many of the genes involved in neural crest production are also used during early development when mutations often lead to embryonic lethality, and thus, functional analyses of the neural crest may not be possible. Accordingly, conditional knockouts in mice or spatiotemporally controlled manipulation of gene expression in other species are necessary to elucidate the role of these genes in neural crest development. Despite the high degree of plasticity and wide array of known neural crest cell contributions, it is crucial to remember that (as discussed above) mutations in neural crest genes such as those involved in EMT can lead to a range of defects. Table 2 summarizes the phenotypes observed in humans with mutations of neural crest genes together with the known associated human syndromes. A full version of this table including the phenotypes observed in animal models or following experimental alterations in the expression of neural crest genes is available as Supplemental Table 1 (supplemental material available online with this article; doi:10.1172/JCI38109DS1). As most of the neural crest genes are pleiotropic, mutants sometimes exhibit other defects independent of their function in the neural crest. Furthermore, since the neural crest cell population contains cells that are highly proliferative, migratory, and multipotent, some neural crest-derived tumors, such as neuroblastomas and medulloblastomas, have catastrophic effects.

\section{What can developmental EMT teach us about EMT in pathological situations?}

While EMT processes are crucial for the progress of embryonic development and later for wound healing and tissue repair, the abnormal activation of EMT programs can be highly deleterious in the adult (Figure 5), as discussed in another Review in this series (95). The expression of EMT inducers is silenced in the adult organism but can be reactivated in cells where epithelial homeostasis is disturbed, such as during the fibrotic process that occurs during organ degeneration. During renal fibrosis, renal epithelial cells are converted into myofibroblasts through a bona fide EMT (96). The EMT inducer Snail1 is activated in mouse models of renal fibrosis, very likely after the secretion of TGF- $\beta$, a potent Snail inducer (97). Interestingly, Snail activation is sufficient to induce EMT, fibrosis, and renal failure in adult transgenic mice and is highly activated in fibrotic kidneys from patients subjected to nephrectomy (98). 
Although EMT is now considered the first step in the metastatic cascade, its contribution to tumor progression has been neglected until recently (see for instance ref. 99). Even though it seems very likely that malignant cells use the same mechanisms to delaminate from an epithelial tumor as those used by embryonic epithelial cells to delaminate and migrate during development, the difficulties in identifying migratory cancer cells have precluded confirmation of the occurrence of EMT in vivo for many years. Powerful imaging techniques have recently allowed the observation of individual cells migrating from mouse primary tumors (100), and several studies now provide direct evidence that this process occurs in mouse and human carcinomas $(101,102)$. It is interesting to note that the reversibility of the process (MET) observed during embryonic development once the migratory cells have reached their destination, is also at play during the formation of metastasis. Indeed, reexpression of E-cadherin has been observed in axillary lymph nodes (103). This reversibility in gene expression suggests that transcriptional regulation rather than irreversible genetic loss may confer a selective advantage for breast cancer cell progression (104).

In summary, it is critical that EMT inducers are kept silent in the adult to maintain epithelial homeostasis and integrity. Regardless of the disease, the occurrence of EMT in the adult can be considered as the reactivation of similar developmental programs operating at the cellular level, albeit in this case with fatal consequences. Thus, an in-depth understanding of the physiology of the process of EMT during embryonic development may pave the way for the design of specific anti-invasive or antifibrotic drugs.

\section{Acknowledgments}

The work in our laboratories is supported by grants from the Spanish Ministry of Science and Innovation (grants BFU2005-05772, BFU2008-01042, NAN2004-09230-C04-04, CONSOLIDERINGENIO 2010 CSD2007-00017 and CSD2007-00023) and the Generalitat Valenciana (Prometeo/2008/049) to M.A. Nieto; and by NIH grants R01 DE017911 and P50HG004071 to M. BronnerFraser. H. Acloque was supported by the I3P Programme (European Social Fund/MEC) and M.S. Adams by the Morgan fellowship from the Gordon and Betty Moore Foundation.

Address correspondence to: M. Angela Nieto, Instituto de Neurociencias (CSIC-UMH), Avda Ramón y Cajal s/n, San Juan de Alicante 03550, Spain. Phone: 34-965919243; Fax: 34-9659561; E-mail: anieto@umh.es.
1. Thiery,J.P., and Sleeman,J.P.2006. Complex networks orchestrate epithelial-mesenchymal transitions. Nat. Rev. Mol. Cell Biol. 7:131-142.

2. Hay, E.D. 1968. Organization and fine structure of epithelium and mesenchyme in the developing chick embryo. In Epithelial-mesenchymal interactions. R. Fleischmajer and R.E. Billingham, editors. Williams \& Wilkins. Baltimore, Maryland, USA. 31-55.

3. Barrallo-Gimeno, A., and Nieto, M.A. 2005. The Snail genes as inducers of cell movement and survival: implications in development and cancer. Development. 132:3151-3161.

4. Peinado, H., Olmeda, D., and Cano, A. 2007. Snail, Zeb and bHLH factors in tumor progression: an alliance against the epithelial phenotype? Nat. Rev. Cancer. 7:415-428.

5. Moreno-Bueno, G., Portillo, F., and Cano, A. 2008. Transcriptional regulation of cell polarity in EMT and cancer. Oncogene. 27:6958-6969.

6. Nakaya, Y., Sukowati, E.W., Wu, Y., and Sheng, G. 2008. RhoA and microtubule dynamics control cell-basement membrane interaction in EMT during gastrulation. Nat. Cell Biol. 10:765-775.

7. Martin, A.C., Kaschube, M., and Wieschaus, E.F. 2009. Pulsed actin-myosin network contractions drive apical constriction. Nature. 457:495-499.

8. Haraguchi, M., et al. 2008. Snail regulates cellmatrix adhesion by regulation of the expression of integrins and basement membrane proteins. J. Biol. Chem. 283:23514-23523.

9. Gans, C., and Northcutt, R.G. 1983. Neural crest and the origin of vertebrates: a new head. Science. 220:268-273.

10. Pijnenborg, R., Dixon, G., Robertson, W.B., and Brosens, I. 1980. Trophoblastic invasion of human decidua from 8 to 18 weeks of pregnancy. Placenta. 1:3-19.

11. Le Douarin, N., and Kalcheim, C. 1999. The neural crest. Cambridge University Press. Cambridge, Massachusetts, USA. 445 pp.

12. Manzanares, M., and Nieto, M.A. 2003. A celebration of the new head and an evaluation of the new mouth. Neuron. 37:895-898.

13. Perez-Pomares, J.M., and Munoz-Chapuli, R. 2002. Epithelial-mesenchymal transitions: a mesodermal cell strategy for evolutive innovation in Metazoans. Anat. Rec. 268:343-351.
14. Johansson, K.A., and Grapin-Botton, A. 2002. Development and diseases of the pancreas. Clin. Genet. 62:14-23.

15. Tanimizu, N., and Miyajima, A. 2007. Molecular mechanism of liver development and regeneration. Int. Rev. Cytol. 259:1-48.

16. Skromne, I., and Stern, C.D. 2001. Interactions between Wnt and Vg1 signalling pathways initiate primitive streak formation in the chick embryo. Development. 128:2915-2927.

17. Liu, P., et al. 1999. Requirement for Wnt3 in vertebrate axis formation. Nat. Genet. 22:361-365.

18. Popperl, H., et al. 1997. Misexpression of Cwnt8C in the mouse induces an ectopic embryonic axis and causes a truncation of the anterior neuroectoderm. Development. 124:2997-3005.

19. Chea, H.K., Wright, C.V., and Swalla, B.J. 2005. Nodal signaling and the evolution of deuterostome gastrulation. Dev. Dyn. 234:269-278.

20. Shah, S.B., et al. 1997. Misexpression of chick Vg1 in the marginal zone induces primitive streak formation. Development. 124:5127-5138.

21. Andersson, O., Bertolino, P., and Ibanez, C.F. 2007. Distinct and cooperative roles of mammalian $\mathrm{Vg} 1$ homologs GDF1 and GDF3 during early embryonic development. Dev. Biol. 311:500-511.

22. Varlet, I., Collignon, J., and Robertson, E.J. 1997. nodal expression in the primitive endoderm is required for specification of the anterior axis during mouse gastrulation. Development. 124:1033-1044.

23. Bertocchini, F., and Stern, C.D. 2002. The hypoblast of the chick embryo positions the primitive streak by antagonizing nodal signaling. Dev. Cell. 3:735-744.

24. Perea-Gomez, A., et al. 2002. Nodal antagonists in the anterior visceral endoderm prevent the formation of multiple primitive streaks. Dev. Cell. 3:745-756.

25. Ciruna, B., and Rossant, J. 2001. FGF signaling regulates mesoderm cell fate specification and morphogenetic movement at the primitive streak. Dev. Cell. 1:37-49.

26. Mathieu, J., et al. 2004. Nodal and Fgf pathways interact through a positive regulatory loop and synergize to maintain mesodermal cell populations. Development. 131:629-641.

27. Nieto, M.A. 2002. The snail superfamily of zincfinger transcription factors. Nat. Rev. Mol. Cell Biol.
3:155-166.

28. Nieto, M.A., Sargent, M.G., Wilkinson, D.G., and Cooke, J. 1994. Control of cell behavior during vertebrate development by Slug, a zinc finger gene. Science. 264:835-839.

29. Carver, E.A., Jiang, R., Lan, Y., Oram, K.F., and Gridley, T. 2001. The mouse snail gene encodes a key regulator of the epithelial-mesenchymal transition. Mol. Cell. Biol. 21:8184-8188.

30. Kasai, Y., Nambu, J.R., Lieberman, P.M., and Crews, S.T. 1992. Dorsal-ventral patterning in Drosophila: DNA binding of snail protein to the single-minded gene. Proc. Natl. Acad. Sci. U. S. A. 89:3414-3418.

31. Ip, Y.T., Park, R.E., Kosman, D., Bier, E., and Levine, M. 1992. The dorsal gradient morphogen regulates stripes of rhomboid expression in the presumptive neuroectoderm of the Drosophila embryo. Genes Dev. 6:1728-1739.

32. Heisenberg, C.P., and Solnica-Krezel, L. 2008. Back and forth between cell fate specification and movement during vertebrate gastrulation. Curr. Opin. Genet. Dev. 18:311-316.

33. Blanco, M.J., et al. 2007. Snail1a and Snail1b cooperate in the anterior migration of the axial mesendoderm in the zebrafish embryo. Development. 134:4073-4081.

34. Savagner, P., et al. 2005. Developmental transcription factor slug is required for effective re-epithelialization by adult keratinocytes. J. Cell Physiol. 202:858-866

35. Arnold, S.J., Hofmann, U.K., Bikoff, E.K., and Robertson, E.J. 2008. Pivotal roles for eomesodermin during axis formation, epithelium-to-mesenchyme transition and endoderm specification in the mouse. Development. 135:501-511.

36. Lindsley, R.C., et al. 2008. Mesp1 coordinately regulates cardiovascular fate restriction and epithelial-mesenchymal transition in differentiating ESCs. Cell Stem Cell. 3:55-68.

37. Kitajima, S., Takagi, A., Inoue, T., and Saga, Y. 2000. MesP1 and MesP2 are essential for the development of cardiac mesoderm. Development. 127:3215-3226.

38. Cano, A., et al. 2000. The transcription factor snail controls epithelial-mesenchymal transitions by repressing E-cadherin expression. Nat. Cell Biol. 2:76-83.

39. Batlle, E., et al. 2000. The transcription factor snail 
is a repressor of E-cadherin gene expression in epithelial tumor cells. Nat. Cell Biol. 2:84-89.

40. Bolos, V., et al. 2003. The transcription factor Slug represses E-cadherin expression and induces epithelial to mesenchymal transitions: a comparison with Snail and E47 repressors. J. Cell Sci. 116:499-511.

41. Ikenouchi, J., Matsuda, M., Furuse, M., and Tsukita, S. 2003. Regulation of tight junctions during the epithelium-mesenchyme transition: direct repression of the gene expression of claudins/occludin by Snail. J. Cell Sci. 116:1959-1967.

42. Zohn, I.E., et al. 2006. p38 and a p38-interacting protein are critical for downregulation of E-cadherin during mouse gastrulation. Cell. 125:957-969.

43. Deng, C.X., et al. 1994. Murine FGFR-1 is required for early postimplantation growth and axial organization. Genes Dev. 8:3045-3057.

44. Sun, X., Meyers, E.N., Lewandoski, M., and Martin, G.R. 1999. Targeted disruption of Fgf8 causes failure of cell migration in the gastrulating mouse embryo. Genes Dev. 13:1834-1846.

45. Mueller, A.G., et al. 2002. Embryonic lethality caused by apoptosis during gastrulation in mice lacking the gene of the ADP-ribosylation factorrelated protein 1. Mol. Cell. Biol. 22:1488-1494.

46. Zahn, C., et al. 2008. ADP-ribosylation factor-like GTPase ARFRP1 is required for trans-Golgi to plasma membrane trafficking of E-cadherin. J. Biol. Chem. 283:27179-27188.

47. Lee, J.D., Silva-Gagliardi, N.F., Tepass, U., McGlade, C.J., and Anderson, K.V. 2007. The FERM protein Epb4.115 is required for organization of the neural plate and for the epithelial-mesenchymal transition at the primitive streak of the mouse embryo. Development. 134:2007-2016.

48. Hirano, M., Hashimoto, S., Yonemura, S., Sabe, H., and Aizawa, S. 2008. EPB41L5 functions to posttranscriptionally regulate cadherin and integrin during epithelial-mesenchymal transition. J. Cell Biol. 182:1217-1230.

49. Stemmer, V., de Craene, B., Berx, G., and Behrens, J. 2008. Snail promotes Wnt target gene expression and interacts with beta-catenin. Oncogene. 27:5075-5080.

50. Whiteman, E.L., Liu, C.J., Fearon, E.R., and Margolis, B. 2008. The transcription factor snail represses Crumbs3 expression and disrupts apico-basal polarity complexes. Oncogene. 27:3875-3879.

51. Lee, H.S., Nishanian, T.G., Mood, K., Bong, Y.S., and Daar, I.O. 2008. EphrinB1 controls cell-cell junctions through the Par polarity complex. Nat. Cell Biol. 10:979-986.

52. Jorda, M., et al. 2005. Upregulation of MMP-9 in MDCK epithelial cell line in response to expression of the Snail transcription factor. J. Cell Sci. 118:3371-3385.

53. Miyoshi, A., et al. 2004. Snail and SIP1 increase cancer invasion by upregulating MMP family in hepatocellular carcinoma cells. Br. J. Cancer. 90:1265-1273.

54. Mitiku, N., and Baker, J.C. 2007. Genomic analysis of gastrulation and organogenesis in the mouse. Dev. Cell. 13:897-907.

55. Eakin, G.S., and Behringer, R.R. 2004. Gastrulation in other mammals and humans. In Gastrulation. From cells to embryo. C.D. Stern, editor. Cold Spring Harbor Laboratory Press. Cold Spring Harbor, New York, USA. 275-287.

56. Denker, H.W., Behr, R., Heneweer, C., Viebahn, C., and Thie, M. 2007. Epithelial-mesenchymal transition in Rhesus monkey embryonic stem cell colonies: a model for processes involved in gastrulation? Cells Tissues Organs. 185:48-50.

57. Dvash, T., et al. 2004. Temporal gene expression during differentiation of human embryonic stem cells and embryoid bodies. Hum. Reprod. 19:2875-2883.

58. Eastham, A.M., et al. 2007. Epithelial-mesenchymal transition events during human embryonic stem cell differentiation. Cancer Res. 67:11254-11262.

59. Selleck, M.A., and Bronner-Fraser, M. 1995. Origins of the avian neural crest: the role of neural plateepidermal interactions. Development. 121:525-538.

60. Meulemans, D., and Bronner-Fraser, M. 2004. Gene-regulatory interactions in neural crest evolution and development. Dev. Cell. 7:291-299.

61. Sauka-Spengler, T., and Bronner-Fraser, M. 2006. Development and evolution of the migratory neural crest: a gene regulatory perspective. Curr. Opin. Genet. Dev. 16:360-366.

62. Sauka-Spengler, T., and Bronner-Fraser, M. 2008. A gene regulatory network orchestrates neural crest formation. Nat. Rev. Mol. Cell Biol. 9:557-568.

63. Liem, K.F., Jr., Tremml, G., Roelink, H., and Jessell, T.M. 1995. Dorsal differentiation of neural plate cells induced by BMP-mediated signals from epidermal ectoderm. Cell. 82:969-979.

64. Garcia-Castro, M.I., Marcelle, C., and Bronner-Fraser, M. 2002. Ectodermal Wnt function as a neural crest inducer. Science. 297:848-851.

65. Carmona-Fontaine, C., et al. 2008. Contact inhibition of locomotion in vivo controls neural crest directional migration. Nature. 456:957-961.

66. Sela-Donenfeld, D., and Kalcheim, C. 1999. Regulation of the onset of neural crest migration by coordinated activity of BMP4 and Noggin in the dorsal neural tube. Development. 126:4749-4762.

67. Karafiat, V., et al. 2005. Transcription factor c$\mathrm{Myb}$ is involved in the regulation of the epithelialmesenchymal transition in the avian neural crest. Cell. Mol. Life Sci. 62:2516-2525.

68. Sela-Donenfeld, D., and Kalcheim, C. 2000. Inhibition of noggin expression in the dorsal neural tube by somitogenesis: a mechanism for coordinating the timing of neural crest emigration. Development. 127:4845-4854

69. Coles, E., Christiansen, J., Economou, A., BronnerFraser, M., and Wilkinson, D.G. 2004. A vertebrate crossveinless 2 homologue modulates BMP activity and neural crest cell migration. Development. 131:5309-5317.

70. Burstyn-Cohen, T., Stanleigh, J., Sela-Donenfeld, D., and Kalcheim, C. 2004. Canonical Wnt activity regulates trunk neural crest delamination linking $\mathrm{BMP} /$ noggin signaling with G1/S transition. Development. 131:5327-5339.

71. Glavic, A., Silva, F., Aybar, M.J., Bastidas, F., and Mayor, R. 2004. Interplay between Notch signaling and the homeoprotein Xiro1 is required for neural crest induction in Xenopus embryos. Development. 131:347-359.

72. Cheung, M., et al. 2005. The transcriptional control of trunk neural crest induction, survival, and delamination. Dev. Cell. 8:179-192.

73. Dottori, M., Gross, M.K., Labosky, P., and Goulding, M. 2001. The winged-helix transcription factor Foxd3 suppresses interneuron differentiation and promotes neural crest cell fate. Development. 128:4127-4138

74. Kos, R., Reedy, M.V., Johnson, R.L., and Erickson, C.A. 2001. The winged-helix transcription factor FoxD3 is important for establishing the neural crest lineage and repressing melanogenesis in avian embryos. Development. 128:1467-1479.

75. del Barrio, M.G., and Nieto, M.A. 2002. Overexpression of Snail family members highlights their ability to promote chick neural crest formation. Development. 129:1583-1593.

76. Liu, J.P., and Jessell, T.M. 1998. A role for rhoB in the delamination of neural crest cells from the dorsal neural tube. Development. 125:5055-5067.

77. Sock, E., Schmidt, K., Hermanns-Borgmeyer, I. Bosl, M.R., and Wegner, M. 2001. Idiopathic weight reduction in mice deficient in the high-mobility-group transcription factor Sox8. Mol. Cell. Biol. 21:6951-6959

78. Cheung, M., and Briscoe, J. 2003. Neural crest development is regulated by the transcription factor Sox9. Development. 130:5681-5693.
79. Perez-Alcala, S., Nieto, M.A., and Barbas, J.A. 2004. LSox 5 regulates $\mathrm{RhoB}$ expression in the neural tube and promotes generation of the neural crest. Development. 131:4455-4465.

80. Van de Putte, T., et al. 2003. Mice lacking ZFHX1B, the gene that codes for Smad-interacting protein-1, reveal a role for multiple neural crest cell defects in the etiology of Hirschsprung disease-mental retardation syndrome. Am. J. Hum. Genet. 72:465-470.

81. Taneyhill, L.A., Coles, E.G., and Bronner-Fraser, M. 2007. Snail2 directly represses cadherin6B during epithelial-to-mesenchymal transitions of the neural crest. Development. 134:1481-1490.

82. Shoval, I., Ludwig, A., and Kalcheim, C. 2007. Antagonistic roles of full-length $\mathrm{N}$-cadherin and its soluble BMP cleavage product in neural crest delamination. Development. 134:491-501.

83. Akitaya, T., and Bronner-Fraser, M. 1992. Expression of cell adhesion molecules during initiation and cessation of neural crest cell migration. Dev. Dyn. 194:12-20.

84. Nakagawa, S., and Takeichi, M. 1998. Neural crest emigration from the neural tube depends on regulated cadherin expression. Development. 125:2963-2971.

85. Vallin, J., Girault, J.M., Thiery, J.P., and Broders, F. 1998. Xenopus cadherin-11 is expressed in different populations of migrating neural crest cells. Mech. Dev. 75:171-174.

86. Erickson, C.A., and Perris, R. 1993. The role of cellcell and cell-matrix interactions in the morphogenesis of the neural crest. Dev. Biol. 159:60-74.

87. Parsons, S.L., Watson, S.A., Brown, P.D., Collins, H.M., and Steele, R.J. 1997. Matrix metalloproteinases. Br. J. Surg. 84:160-166

88. Robbins, J.R., McGuire, P.G., Wehrle-Haller, B., and Rogers, S.L. 1999. Diminished matrix metalloproteinase 2 (MMP-2) in ectomesenchyme-derived tissues of the Patch mutant mouse: regulation of MMP-2 by PDGF and effects on mesenchymal cell migration. Dev. Biol. 212:255-263.

89. Duong, T.D., and Erickson, C.A. 2004. MMP-2 plays an essential role in producing epithelialmesenchymal transformations in the avian embryo. Dev. Dyn. 229:42-53.

90. Perris, R., and Perissinotto, D. 2000. Role of the extracellular matrix during neural crest cell migration. Mech. Dev. 95:3-21.

91. Moreno-Bueno, G., et al. 2006. Genetic profiling of epithelial cells expressing E-cadherin repressors reveals a distinct role for Snail, Slug, and E47 factors in epithelial-mesenchymal transition. Cancer Res. 66:9543-9556.

92. Giehl, K., and Menke, A. 2008. Microenvironmental regulation of E-cadherin-mediated adherens junctions. Front. Biosci. 13:3975-3985.

93. Wu, S.Y., and McClay, D.R. 2007. The Snail repressor is required for PMC ingression in the sea urchin embryo. Development. 134:1061-1070.

94. Murray, S.A., and Gridley, T. 2006. Snail family genes are required for left-right asymmetry determination, but not neural crest formation, in mice. Proc. Natl. Acad. Sci. U. S. A. 103:10300-10304.

95. Kalluri, R., and Weinberg, R.A. 2009. The basics of epithelial-mesenchymal transition. J. Clin. Invest. 119:1420-1428.

96. Iwano, M., et al. 2002. Evidence that fibroblasts derive from epithelium during tissue fibrosis. J. Clin. Invest. 110:341-350.

97. Sato, M., Muragaki, Y., Saika, S., Roberts, A.B., and Ooshima, A. 2003. Targeted disruption of TGF-beta1/Smad3 signaling protects against renal tubulointerstitial fibrosis induced by unilateral ureteral obstruction. J. Clin. Invest. 112:1486-1494.

98. Boutet, A., et al. 2006. Snail activation disrupts tissue homeostasis and induces fibrosis in the adult kidney. EMBO J. 25:5603-5613.

99. Tarin, D., Thompson, E.W., and Newgreen, D.F. 
2005. The fallacy of epithelial mesenchymal transition in neoplasia. Cancer Res. 65:5996-6000; discussion 6000-6001.

100. Condeelis, J., and Segall, J.E. 2003. Intravital imaging of cell movement in tumors. Nat. Rev. Cancer. 3:921-930.

101.Brabletz, T., et al. 2001. Variable beta-catenin expression in colorectal cancers indicates tumor progression driven by the tumor environment. Proc. Natl. Acad. Sci. U. S. A. 98:10356-10361.

102. Trimboli, A.J., et al. 2008. Direct evidence for epithelial-mesenchymal transitions in breast cancer. Cancer Res. 68:937-945.

103.Bukholm, I.K., Nesland, J.M., and Borresen-Dale, A.L. 2000. Re-expression of E-cadherin, alphacatenin and beta-catenin, but not of gammacatenin, in metastatic tissue from breast cancer patients. J. Pathol. 190:15-19.

104. Cheng, C.W., et al. 2001. Mechanisms of inactivation of E-cadherin in breast carcinoma: modification of the two-hit hypothesis of tumor suppressor gene. Oncogene. 20:3814-3823.

105. Gilbert, S.F. 2000. Developmental biology. 6th edition. Sinauer Associates, Inc., Publishers. Sunderland, Massachusetts, USA. 709 pp.

106.Dupin, E., Calloni, G., Real, C., Goncalves-Trentin, A., and Le Douarin, N.M. 2007. Neural crest progenitors and stem cells. C. R. Biol. 330:521-529.

107. Christ, B., Huang, R., and Scaal, M. 2007. Amniote somite derivatives. Dev. Dyn. 236:2382-2396.

108.Gros, J., Manceau, M., Thome, V., and Marcelle, C. 2005. A common somitic origin for embryonic muscle progenitors and satellite cells. Nature.
435:954-958.

109.Christ, B., Jacob, M., and Jacob, H.J. 1983. On the origin and development of the ventrolateral abdominal muscles in the avian embryo. An experimental and ultrastructural study. Anat. Embryol. (Berl.). 166:87-101.

110.Eichmann, A., et al. 2005. Vascular development: from precursor cells to branched arterial and venous networks. Int. J. Dev. Biol. 49:259-267.

111. Tavian, M., and Peault, B. 2005. Embryonic development of the human hematopoietic system. Int. J. Dev. Biol. 49:243-250.

112.Karl, J., and Capel, B. 1998. Sertoli cells of the mouse testis originate from the coelomic epithelium. Dev. Biol. 203:323-333.

113.Hay, E.D. 1995. An overview of epitheliomesenchymal transformation. Acta Anat. (Basel). 154:8-20.

114.Nakajima, Y., Yamagishi, T., Hokari, S., and Nakamura, H. 2000. Mechanisms involved in valvuloseptal endocardial cushion formation in early cardiogenesis: roles of transforming growth factor (TGF)-beta and bone morphogenetic protein (BMP). Anat. Rec. 258:119-127.

115.Milunsky, J.M., et al. 2008. TFAP2A mutations result in branchio-oculo-facial syndrome. Am. J. Hum. Genet. 82:1171-1177.

116.Favier, R., et al. 2003. Paris-Trousseau syndrome: clinical, hematological, molecular data of ten new cases. Thromb. Haemost. 90:893-897.

117. Alkhateeb, A., Fain, P.R., and Spritz, R.A. 2005 Candidate functional promoter variant in the FOXD3 melanoblast developmental regulator gene in autosomal dominant vitiligo. J. Invest. Dermatol. 125:388-391.

118. Wang, Q., et al. 2008. Pax genes in embryogenesis and oncogenesis. J. Cell. Mol. Med. 12:2281-2294.

119.Zweier, C., et al. 2002. "Mowat-Wilson" syndrome with and without Hirschsprung disease is a distinct, recognizable multiple congenital anomaliesmental retardation syndrome caused by mutations in the zinc finger homeo box $1 \mathrm{~B}$ gene. Am. J. Med. Genet. 108:177-181.

120.Spritz, R.A., Chiang, P.W., Oiso, N., and Alkhateeb, A. 2003. Human and mouse disorders of pigmentation. Curr. Opin. Genet. Dev. 13:284-289.

121. Kwok, C., et al. 1995. Mutations in SOX9, the gene responsible for Campomelic dysplasia and autosomal sex reversal. Am. J. Hum. Genet. 57:1028-1036.

122.Pingault, V., et al. 1998. SOX10 mutations in patients with Waardenburg-Hirschsprung disease. Nat. Genet. 18:171-173.

123.Yagi, H., et al. 2003. Role of TBX1 in human del22q11.2 syndrome. Lancet. 362:1366-1373.

124.Loeys, B.L., et al. 2005. A syndrome of altered cardiovascular, craniofacial, neurocognitive and skeletal development caused by mutations in TGFBR1 or TGFBR2. Nat. Genet. 37:275-281.

125.Dixon, M.J. 1996. Treacher Collins syndrome. Hum. Mol. Genet. 5:1391-1396.

126. Howard, T.D., et al. 1997. Mutations in TWIST, a basic helix-loop-helix transcription factor, in Saethre-Chotzen syndrome. Nat. Genet. 15:36-41.

127. el Ghouzzi, V., et al. 1997. Mutations of the TWIST gene in the Saethre-Chotzen syndrome. Nat. Genet. 15:42-46. 